\title{
Exploring the Design Platform in Industrialized Housing for Efficient Design and Production of Customized Houses
}

\author{
Samuel ANDRÉ ${ }^{1}$, Martin LENNARTSSON and Fredrik Elgh \\ Jönköping University, Sweden
}

\begin{abstract}
Industrialized house-building (IHB) is a sector offering unique products by adopting an engineer-to-order (ETO) strategy. Customer satisfaction is achieved by adaptation of product solutions and the fast-paced introduction of new technology in combination with short lead-times and cost-efficient production. Product platforms is acknowledged as a strategic enabler for mass customization and increased competitiveness. The strategy has been a necessity in the mechanical industry for several decades. However, for IHB, platforms have only gained interest in recent years. In general, ETO companies struggle with adopting the common product platform approach, set by pre-defined modules and components. Predefinitions require standardization of the product offer which reduces the customization ability which is regarded as a competitive edge. The Design Platform (DP) approach was developed aimed to support ETO companies by utilizing different types of engineering assets in a coherent transdisciplinary model enabling efficient customization. The long-term aim of this work is to investigate and support the DP applicability in IHB to increase efficiency in development and delivery. For this article, data were gathered from a single case study, including workshops with company representatives combined with interviews and document analysis. Based on the data analysis, engineering assets were identified and characterized. Further, a conceptual PLM solution is proposed and outlined to support the DP application combined with the assets. The results suggest that a PLM system can host parts of the DP and that it is applicable in IHB.
\end{abstract}

Keywords. Customization, Product Platform, ETO, Industrialized Housing, PLM

\section{Introduction}

Companies are continuously faced with requirements regarding technological novelty, shorter time to market, higher levels of functionality and lower prices on their products. This especially applies to companies developing and manufacturing highly customized products. Customization is referred to as abilities and strategies that aim at the design and manufacture of tailored products for individual customers. Depending on where the customer is introduced in the order process, four different business models have been proposed: engineer-to-order (ETO), modify-to-order, configure-to-order, and select variant [1]. For the latter two, product platforms have gained success as enablers for efficient customization. In general, product platforms have been widely accepted to serve a wide range of products while maintaining business efficiency. A product

\footnotetext{
${ }^{1}$ Corresponding Author, Email: samuel.andre@ju.se.
} 
platform approach can be defined as the development and implementation of technology, components or subsystems that are shared across multiple products [2].

Product platforms have also proved to prolong the average product life-cycle and enable both higher aggregate sales and aggregate gross profit margins over the product life-cycle compared to products which are not derived from a platform. Early descriptions focused on efficiently providing a product variety while keeping internal variation low and thereby reach a higher level of standardization in production [3]. Also, platforms have served as a means to efficiently and parallel reach customer segments by featuring commonality in product components and interfaces. Modularization is a critical enabler for mass customization and platform thinking. Stjepandić et al. [4] outline several developments and tool implementations of modularity in the context of concurrent engineering, concluding that a current trend is to combine and integrate different technologies such as advanced CAD systems, product configurators, agent-based systems, and PLM systems. Platforms and their associated variants pose challenges for conventional PLM systems on the market [5]. Bondar and Stjepandic [6] presents support and an approach to cope with challenges regarding the co-creation of shared interfaces and modules. Small companies offering customized products are limited to work project-based. [7] proposes a computer system allowing these companies to capture, store and access project knowledge.

Recent research has focused on product platforms using a more abstract definition; these platforms aim to reuse more of the skills and knowledge (i.e. assets) created in a given company to reach higher efficiency during development. Recent research has even questioned whether companies could afford not to apply a platform [8]. However, how to apply a platform strategy for ETO-companies, is still to be explored. Component-oriented product platforms tend to require focused platform development and late-stage customer involvement, which in turn requires knowledge about which future variants are to be derived from the platform.

According to Gosling and Naim [9], construction is described as an ETO-sector. [10] defines industrialized house-building (IHB) as a thoroughly developed housebuilding process with a well-suited organization for efficient management, preparation, and control of the included activities, material flows, resources and results for which prefabricated components are used in order to create maximum customer value. Thus, a move towards IHB means a shift from strictly project-based production to a more process-oriented production [11]. Competitiveness relies on flexibility, delivery time predictability, quality level and cost [12]. Therefore, a key element is information management, i.e. in repetitive production, the process is more vulnerable to erroneous information. In IHB, customer demands are met by adaptation of product solutions and rapid implementation of novel technology combined with efficient production, where product design is carried out in collaboration with the clients [13]. The building system is a critical asset [14] and the boundaries decide the solution range. The difficulty is when these building systems appear in market segments with high levels of customizations. In essence, the challenge is to balance standardization and customization [15] to not either compromise customer demands or production efficiency. Thus, there has been an increasing focus on the platform concept in the construction sector [16]. Further, [13] stressed that despite the presence of a platform strategy, external efficiency and customized solutions were prioritized over the internal efficiency and the platform. To become successful in product design within housebuilding, the key is to coordinate these two entities [17]. Both Jensen et al. [18] and Jansson [19] have observed difficulties when a platform concept is introduced. When 
synthesizing using the previous literature, it is evident that to achieve the potential of a platform strategy in industrialized house-building it is essential to know the platform scope, i.e. what are the prevailing assets and the network binding these assets together. Otherwise, it will be difficult to measure the efficiency and condition of the platform. Product design and production are carried out in projects, which is an obstacle for the ability to develop generic solutions to be reused in upcoming projects.

The Design Platform (DP) [20] was proposed to enable the efficiency promised by product platform approaches to companies with an ETO business approach which traditionally have not been able to utilize product platforms efficiently. The focus is on creation, management, and maintenance of engineering assets that are used in the process of designing and producing products. Besides physical components and modules, a DP is founded on the re-use of assets which can be of many different types and that often are ill-structured and un-formalized.

As a response to the lack of platform models for ETO companies, the DP approach was proposed [20]. The aim of the model and approach is to enable the structure and reuse of company assets in environments where customer requirements are specific and tend to change during and in between projects. The DP supports a transdisciplinary environment [21] and is constructed by different objects embodying knowledge on processes, synthesis resources, product constructs, assessments resources, solutions, projects, and constraint. These objects can be but are not limited to, physical parts since design reuse can be practiced on an array of different types of embodied knowledge. When previously developed solutions cannot be reused directly, there is often a way to apply generic guidelines, process descriptions, calculations etc in order to arrive at new solutions, guaranteeing the use of verified knowledge in the process. The core of the DP is generic product structures and generic process flows which are related to each other. The building blocks of the structures and flows are then related to the different kinds of assets supporting their realization. These assets encapsulate knowledge from different disciplines related to different stakeholders and lifecycle phases. This essentially creates a coherent transdisciplinary platform description consisting of heterogeneous assets which are allowed to evolve over time.

Previous research on the application of the DP has focused on ETO-companies within the mechanical industry. The contribution of this paper, however, lies in the application and conceptual support of the DP in the IHB industry with the aim of giving these companies the means to become more efficient. The purpose of this paper is to support the customization ability for IHB companies striving to offer individualized products but with a strategy which includes a factory. This is accomplished by analyzing the as-is state in the company in terms of existing engineering assets and by proposing a to-be state using the DP approach and PLM support. The IHB setting also allows for proposing changes to the DP model to fit this industry to a larger extent.

This work has used a Design research methodology (DRM) as proposed by Blessing and Chakrabarti [22]. The methodology describes four stages: Research clarification (RC), Descriptive study I (DSI), Prescriptive study (PS), Descriptive study II (DSII). This article is positioned in between DSI and PS since it involves the analysis and description of a company along with a conceptual proposal for how to improve the situation for the company and similar companies. The used data collection methods consist of in-depth interviews, document reviews, method development, and workshops. Types of reviewed documents include drawings needed to produce standard configurations, but also design templates and standard operations (STD), which 
describe a variety of issues, e.g. technical solutions, bill of material and way of working. The interview respondents were the technical manager and key individuals regarding the structural system (2) and building services (electricity and HVAC).

\section{Result and analysis}

This section presents the case company, the result of an interview study and a document review. Finally, an analysis of the outcome is presented.

\subsection{Case description}

The case company offers products such as schools, kindergartens, elderly homes, and offices. Knowledge about the clients' operations is decisive. The overall strategy is to complete up to $90 \%$ of production off-site in a factory. Standardization in production is a fundament in the business concept. The building system is based on volumetric elements in turn-key contracts, meaning that the company is covering all disciplines and the entire construction process. The product portfolio attracts public clients with large budgets. Consequently, these clients are not afraid of setting a narrow frame of demands or to continuously alter the demands in the projects. The continuous platform development in the company is a recurring way of working in the industry [10]. The two parallel tracks, the technical platform, and the process platform are distinguished by developing new product solutions and developing the process to complete the contracts. Given the characteristics of the construction industry and the amount of money invested in the products, there is no prototyping. Rather, development is carried out in actual projects and if the evaluation prescribes, solutions are incorporated into the platform. The product selected for investigation is a dormitory with a floor plan where apartments are positioned in file in two floors. Each apartment is defined by a single volume element. As an initial study object, this project was found suitable as it is not overly complex but still possess the potential to demonstrate the design platform.

\subsection{Interview results on company assets}

The interviews aimed at identifying intangible sources of knowledge, connected to inherent know-how and experience, which has the potential to become asset objects aligned with DP approach. In Table 1 these asset potentials are presented from the perspective of three prevailing domains in industrialized house-building.

In addition to the listed potential assets, know-how on generic project management and turnkey contracts can be added. As for sales and production, the potential assets are rather fixed. It is crucial to excel in market knowledge to stay competetive. Consequently, to be successful in the segment that the case company adheres to, governmental procurement and the capacity of the product portfolio are decisive. Product families and house models, based on the building system and previous house models, are developed to meet the needs of the market. The platform construct follows a modular mindset. Still, the platform is more dependent on the production layout and process rather than the ability to configure products. Knowledge of the production process and factory limitations are fundaments of an industrialized house-building strategy. Conjointly, experience feedback and standard protocols are ways to maintain efficiency. 
Most of the potentials can be referred to the design phase, which aligns with the description of IHB being an ETO sector. The listed potential assets are all crucial to master to not destroy the efficiency of the fixed asset, the factory. Still, some flexibility must be allowed for the sales department to not lose contracts on minor adaptations to the building system. However, the platform is not documented and not really defined and consequently an overview and holistic approach is missing. Instead, an overwhelming number of documents occupy the shared folder structure on the server, exceeding 1.5 million files. While many of the presented potentials are current, the guideline system (STD) is, in addition, the overall knowledge repository in the company.

Table 1. Potential asset objects in the case company.

\begin{tabular}{ccc}
\hline Sales & Design & Production \\
\hline $\begin{array}{c}\text { The offered range of products and } \\
\text { built-in knowledge }\end{array}$ & $\begin{array}{c}\text { Allowed technical solutions, } \\
\text { customization/ } \\
\text { Adaptability }\end{array}$ & $\begin{array}{c}\text { The production process, } \\
\text { build-up, and know-how }\end{array}$ \\
\hline $\begin{array}{c}\text { Government procurement } \\
\text { knowledge }\end{array}$ & $\begin{array}{c}\text { Regulations updates, energy } \\
\text { efficiency, and sustainability }\end{array}$ & $\begin{array}{c}\text { Disturbance log - experience } \\
\text { feedback }\end{array}$ \\
\hline Market knowledge and demands & REVIT (CAD software) & Factory limitations \\
\hline & Guideline-system (STD) & Protocols and checklists \\
\hline
\end{tabular}

\subsection{Document review and mapping of the guideline system}

There are nine different series in the guideline system. The headings (Table 2) are sorted according to disciplines in the overall construction process. Thus, the logic is based on the guilds that are working as subcontractors and suppliers rather than product architecture, modules or parts. In traditional construction projects, a main contractor is responsible for coordinating work and procure sub-contractors and suppliers and then these actors carry out their part only. However, moving towards a factory-based production, this division is no longer logical. The content of the STDs ranges from different standards to guidelines in both design and production but also requirements.

The document review followed these steps, (1) gather all construction documents (CD) for the selected house model; (2) extract the referenced STDs; (3) Follow the paths from the CDs to the overall STD database; (4) Describing the network of couplings in the database between STDs using a Design Structure Matrix [23] approach.

Among the published CDs (162) for the selected project there were references to 30 exclusive STDs. Similar elements refer to the same STDs, e.g. inner walls where references appear repeatedly, mostly to HVAC solutions. There are also references to other construction documents within the project. When applying the DSM approach in the investigation of the database of STDs, a network structure presents itself. Different STDs refer to other STDs, at the extreme, there are six levels in the hierarchy, but more commonly two to three levels. In total 82 STDs are referenced in the overall project. Thus, from the 30 STDs in the construction documents, an additional 52 were added through connections between STDs. There are references to the same document on different levels, i.e. the same STD can exist on multiple levels in the hierarchy. Also, there are circular references where one document points to another document which points back to the first one. Among the 30 STDs in the CDs, the series 1002-1006 were covered, which means that foundation, electricity and room completion were not included i.e. not referenced by the project documentation and thus no documentation specified those parts leaving it up to production workers. In the subsequent DSM analysis, series 1000, 1001 and 1007 were referenced, while 1008 remained excluded. 
An overwhelming count belongs to series 1002, 19 references in the CDs and a grand total of 53 after the DSM was completed.

These results show that the STD system has a weak connection to the platform concept that the company employs. The document identifiers are based on the guild system and not levels in a product architecture. It can also be seen that the framing is highly specified compared to other areas leaving them with a low level of standardization.

Table 2. The series of STDs and the number of references, construction documents (CD) and total count from the DSM analysis.

\begin{tabular}{cccc}
\hline Series & Heading & CD & Tot \\
\hline 1000 & Common & 0 & 1 \\
1001 & Foundation & 0 & 6 \\
1002 & Framing & 19 & 53 \\
1003 & Framing completion & 2 & 8 \\
1004 & Layer & 6 & 7 \\
1005 & Water and drain & 2 & 3 \\
1006 & HVAC & 1 & 3 \\
1007 & Electricity & 0 & 2 \\
1008 & Room Completion & 0 & 0 \\
\hline
\end{tabular}

\section{Concept to support the Design Platform for industrialized house building}

In order to support the introduction of the DP, a conceptual proposal (Table 3) and a structured way of managing the identified engineering assets are here presented which is based upon a product lifecycle management system (PLM). The DP is built on an object-oriented model making it suitable to capture assets of different kinds.

\subsection{Process modeling}

Based on the empirical data gathered from interviews there were no formalized processes identified. Some process related potential assets were identified (see Table 1), however, they do not explicitly exist as of today. A list and sequence of data receivers could be identified which can be interpreted as process steps. These steps cover all customer project steps starting with initial customer contact and ending with the finish-

Table 3. PLM system capabilities to support the company.

\begin{tabular}{|c|c|c|}
\hline Name & Description & State of practice \\
\hline $\begin{array}{c}\text { Revision } \\
\text { management }\end{array}$ & $\begin{array}{l}\text { Managing files and objects stored in the } \\
\text { PLM file database. }\end{array}$ & $\begin{array}{l}\text { Documents are stored in an MS file structure } \\
\text { without support for revision management. }\end{array}$ \\
\hline $\begin{array}{l}\text { User and } \\
\text { access } \\
\text { management }\end{array}$ & $\begin{array}{c}\text { Enables different professions within the } \\
\text { company to have different kinds of } \\
\text { access to the data depending on their } \\
\text { role. }\end{array}$ & $\begin{array}{c}\text { The receivers of specific data are not } \\
\text { identified, and different levels of access } \\
\text { cannot be used. }\end{array}$ \\
\hline $\begin{array}{c}\text { Part } \\
\text { management }\end{array}$ & $\begin{array}{l}\text { Allows for modeling and managing } \\
\text { product parts and structures such as } \\
\text { components and assemblies. }\end{array}$ & $\begin{array}{l}\text { Parts are only handled in the CAD software } \\
\text { without an assembly structure. Parts are not } \\
\text { file based in the company CAD system } \\
\text { obstructing reuse between projects. }\end{array}$ \\
\hline $\begin{array}{c}\text { Process } \\
\text { management }\end{array}$ & $\begin{array}{c}\text { Enables keeping track of approval status } \\
\text { and process progression connected to } \\
\text { the data }\end{array}$ & $\begin{array}{l}\text { Many processes are formalized, and no } \\
\text { processes are supported by IT tools. }\end{array}$ \\
\hline $\begin{array}{c}\text { Attribute } \\
\text { management }\end{array}$ & $\begin{array}{l}\text { Allows for enriched descriptions and } \\
\text { different views on objects and linked } \\
\text { data. }\end{array}$ & $\begin{array}{l}\text { No attribute data exist on current documents } \\
\text { except for the data encapsulated in the } \\
\text { documents and the categorization according } \\
\text { to the guild system. Suitable attributes can }\end{array}$ \\
\hline
\end{tabular}




\begin{tabular}{c|c|c}
\hline Link objects & $\begin{array}{c}\text { Makes it possible to link related objects } \\
\text { to each other and attach attributes to the } \\
\text { link. }\end{array}$ & $\begin{array}{c}\text { Existing links are hidden in the documents } \\
\text { and cannot be managed separately from } \\
\text { document content making it hard to get an } \\
\text { overview of how the assets are related. }\end{array}$ \\
\hline $\begin{array}{c}\text { Object } \\
\text { orientation }\end{array}$ & $\begin{array}{c}\text { Separation of different classes of assets } \\
\text { depending on content and designated } \\
\text { use. }\end{array}$ & $\begin{array}{c}\text { Only MS office and CAD file formats are } \\
\text { used which does not communicate content or } \\
\text { use. }\end{array}$ \\
\hline
\end{tabular}

-ing of a house on site. Modeling these as process nodes in the PLM system enables efficient project management and to be able to follow the project progression. Generic engineering assets (in the form of e.g. STD objects) can be linked to each step ensuring the correct documentation at the right time. Some generic product parts can also be linked to the process steps making it clearer where in the process-specific parts are designed and produced. The data receivers are shown in Figure 1.

The first two steps correspond to the sales and design stage whilst difference in dashed lines indicate the preceding production steps in factory and on-site. In addition, general approval flows should be set up for documentation created both inside but also outside projects which builds up the generic platform description. This is to ensure the quality of the documentation which is created.

\subsection{Product structure modeling}

Product structure modeling as it is usually practiced in PLM systems in the mechanical industry is not as common in IHB. Following the DP approach, generic parts are to be identified and modeled as structures. For this specific case, the company has a set of standard houses which have generic features that are suitably captured as generic part structures. The standard houses, which will each have a generic structure modeled, consist of 5 types of school buildings, 4 types of living houses, 2 types of office buildings and 19 types of sheds. Each generic part of the generic structure can hold generic engineering assets which can be utilized for the realization of the part. Figure 2 shows the principle behind how both the generic process together with a generic product structure is instantiated into specific projects where the structure finally becomes a specific instance that can be delivered to a customer. The generic part structure holds (1) the generic Bill of Material (BOM), (2) external requirements such as legal requirements, (3) internal requirements such as limitations in the production, (4) parametric CAD models, (5) carry-over parts, (6) calculation models. The instance part structure is further enriched with (7) the specific BOM, (8) external requirements set by customer, (9) specific 3D and 2D drawings, (10) calculation reports.

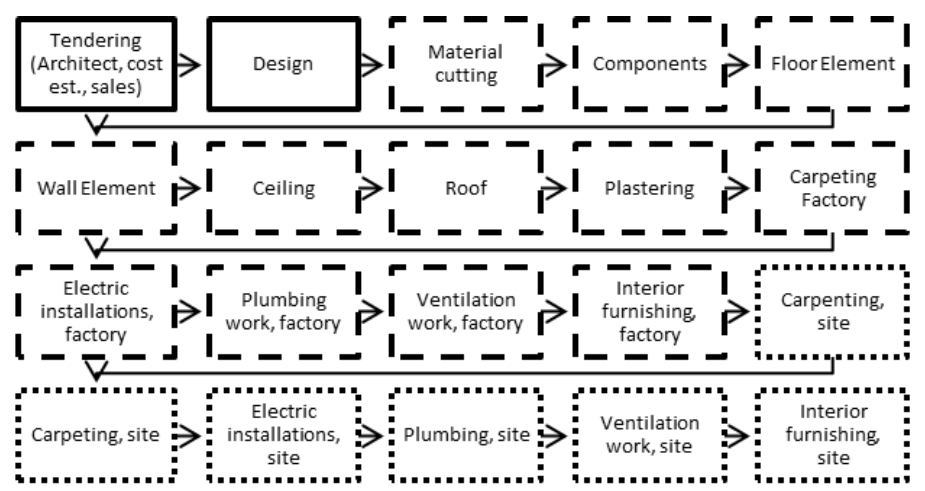

Figure 1. Process steps of house building project. 
By synchronizing a specific ID for each generic structure with each specific ID which is generated for the instances it will be possible to keep the connection between generic structure and instance. Furthermore, integration is needed to the company CAD system in order to synchronize parts, avoid data redundancy and access part properties.

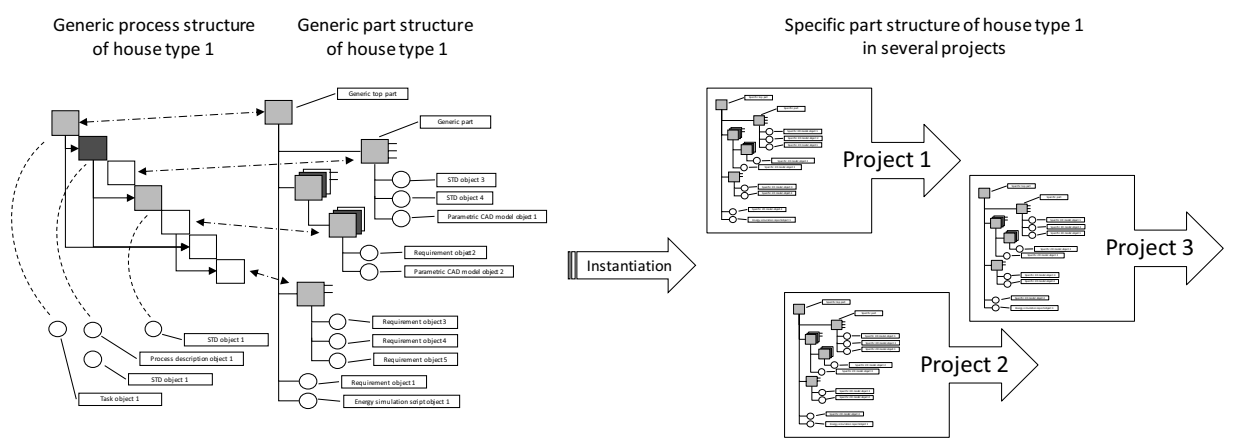

Figure 2. The principles of DP instantiation.

\section{Discussion}

This paper has brought forward a case with a company active in the IHB industry. From the collected empirical data, potential assets have been identified which creates a baseline for DP application. A PLM concept has been brought forward aiming to support the management of these assets. In addition, literature has proposed tools to support e.g. collaborative modular development [6] and project-based development [7] focusing on the mechanical industry. The IHB industry, however, has other kinds of challenges. One of them being the factory in combination with clients that expect a high level of customization traditionally provided by on-site contractors $[18,19]$. A second being the inability to proactively develop and test new products as houses are forced to be produced in specific customer projects due to their size and cost. As of now, the identified assets cannot directly be categorized according to the different types as proposed in the DP approach. This goes specifically for STD which contains many different topics such as requirements and solutions or combinations. As described previously, they can still be incorporated into the PLM concept. The proposal is to divide the STD and to create more suitable classes that support their use and maintenance. By applying the DP, the company can capture, structure, maintain and thereby take advantage of both the prevailing know-how but also the know-how continuously generated from customer projects. By the support of a PLM system where a generic view is combined with an instance view the company can work platform based and make the assets available by linking them to the relevant process step and product part. In turn, this will lead to a more streamlined use of company assets with the ability to make the platform boundaries more obvious. This is crucial to know if customer inquiries are within the platform capacity and can then support the decision process of what projects that are to be accepted.

In order to realize the concept previously described, an asset needs to be further investigated and connected to specific attributes. Engineering assets must be categorized according to what parts they affect, what project process step they concern, 
what type of asset they are, what step in the general building process they concern as well as what type of room they concern. The attribute "room" is specific to the construction sector since it creates a structure of its own and does not easily map to a part structure. Rooms can be seen as a function or the effect of attaching parts to each other in a specific way. Therefore, even though it is considered an object, it will be treated as an attribute for each asset.

Previous research concerning the DP approach has presented details regarding the identification of assets, the modeling of assets, the structuring of assets and the process of creating and supporting the complete DP by computer applications. This paper contributes to the notion that some assets are already existing and formalized in companies e.g. STD. It is therefore crucial that, when setting up the complete DP model, these assets are identified and analyzed. A decision then has to be made if these assets can be kept and incorporated as they are or if they have to be changed in order to fit with the overall approach.

\section{Conclusion}

This paper has investigated a company in the IHB industry in terms of its potential of applying the DP approach. A conceptual PLM system solution has been proposed to support the company in the application and thus enabling higher efficiency. By standardizing house types in the PLM system and connect them to their realizing assets the sales department will be supported in keeping within the platform boundaries. The same information model is used by engineers and production workers which supports the design, production, and delivery of the product at the same time as ensuring reuse and quality. Future work includes the categorization of assets by identifying attributes, critical to IHB, followed by the modeling of a PLM system according to the concept presented in this paper. Expected challenges include integration of a PLM system with the used CAD software. Currently, there is a discrepancy between how structures are modeled in mechanical PLM systems compared to 3D CAD aimed for construction.

\section{Acknowledgment}

The authors would like to thank the involved company, making this research possible, as well as to The Region Jönköping County for funding this research.

\section{References}

[1] Hansen, B.L., Development of industrial variant specification systems, Doctoral dissertation, Technical University of Denmark, 2003.

[2] M.H. Meyer et al., Does Product Platforming Pay Off? Journal of Product Innovation Management, 2018, Vol. 35, Issue 1, pp. 66-87.

[3] M.H. Meyer and A.P. Lehnerd, The power of product platforms - Building value and cost leadership, The Free Press New York, 1997.

[4] J. Stjepandić, E. Ostrosi, A.-J. Fougères, M. Kurth, Modularity and Supporting Tools and Methods, in: J. Stjepandić et al. (eds.): Concurrent Engineering in the $21^{\text {st }}$ Century: Foundations, Developments and Challenges, Springer International Publishing Cham, 2015, pp. 389-420.

[5] H.P.L. Bruun, et al., PLM system support for modular product development. Computers in Industry, 2015. 67: pp. 97-111. 
[6] Bondar, S. and J. Stjepandić. Engineering collaboration in product development of modular products. Advances in Transdisciplinary Engineering, Vol 7: Transdisciplinary Engineering Methods for Social Innovation of Industry 4.0. 2018, pp. 391-400.

[7] Pokojski, J., K. Oleksiński, and J. Pruszyński. Conceptual and detailed design knowledge management in customized production - industrial perspective. Advances in Transdisciplinary Engineering, Vol 7: Transdisciplinary Engineering Methods for Social Innovation of Industry 4.0. 2018, pp. 1064-1073.

[8] H. Johannesson, Emphasizing reuse of generic assets through integrated product and production system development platforms. In: T.W. Simpson, J.R. Jiao, Z. Siddique, K. Hölttä-Otto (eds.) Advances in product family and product platform design: Methods \& application, Springer-Verlag, New York, 2014, pp. 119-146.

[9] J. Gosling and M.M. Naim, Engineer-to-order supply chain management: A literature review and research agenda. International journal of production economics, 2009. 122(2): pp. 741-754.

[10] J. Lessing, Industrialised house-building. Concept and Processes. Lic thesis, Lund University, 2006.

[11] H. Jonsson, Production Strategy in Project Based Production within a House-Building Context. PhD thesis, Linköping University, 2017.

[12] H. Jonsson and M. Rudberg, Classification of production systems for industrialized building: a production strategy perspective. Construction Management and Economics, 2014. 32(1-2): pp. 53-69.

[13] M. Lennartsson and F. Elgh, Exploring Product Development in Industrialized Housing to Facilitate a Platform Strategy. 26th Annual Conference of the International Group for Lean Construction, 18-20 Jul 2018, Chennai, India. 2018.

[14] H. Johnsson, The building system as a strategic asset in industrialised construction. in Nordic Conference on Construction Economics and Organisation: 13/04/2011-15/04/2011. 2011. Danish Building Research Institute, Aalborg University.

[15] J. Gosling, M. Naim and D. Towill, A supply chain flexibility framework for engineer-to-order systems. Production Planning \& Control, 2013. 24(7): pp. 552-566.

[16] S. Thajudeen, M. Lennartsson and F. Elgh. Impact on the Design Phase of Industrial Housing When Applying a Product Platform Approach. in 26th Annual Conference of the International Group for Lean Construction, 18-20 Jul 2018, Chennai, India. 2018.

[17] H. Johnsson, Production strategies for pre-engineering in house-building: exploring product development platforms. Construction Management and Economics, 2013. 31(9): pp. 941-958.

[18] P.Jensen, et al. Improving buildability with platforms and configurators. in Annual Conference of the International Group for Lean Construction: 31/07/2013-02/08/2013. 2013.

[19] Jansson, G., Platforms in industrialised house-building. PhD thesis, 2013, Luleå tekniska universitet.

[20] S. André, et al., The design platform-a coherent platform description of heterogeneous design assets for suppliers of highly customised systems. Journal of Engineering Design, 2017, pp. 1-28.

[21] S. André and F. Elgh, Modeling of transdisciplinary engineering assets using the design platform approach for improved customization ability. Advanced Engineering Informatics, 2018, Vol. 38, pp. 277-290.

[22] L.T. Blessing and A. Chakrabarti, DRM, a design research methodology. Springer, Berlin, 2009.

[23] J. Malmqvist, A classification of matrix-based methods for product modeling. in DS 30: Proceedings of DESIGN 2002, the 7th International Design Conference, Dubrovnik. 2002, pp. 203-210. 